\title{
Consequences of Dutch law on the use of coercive treatment in mania: an example of syndrome specific influence of law on coercive treatment mode Erwin GTM Hartong
}

\author{
Address: Canisius-Wilhelmina General Hospital, po box 9015, 6500GS Nijmegen, Netherlands \\ from WPA Thematic Conference. Coercive Treatment in Psychiatry: A Comprehensive Review \\ Dresden, Germany. 6-8 June 2007 \\ Published: 19 December 2007 \\ BMC Psychiatry 2007, 7(Suppl I):S73 doi:10.1 I86/I47I-244X-7-SI-S73
}

This abstract is available from: http://www.biomedcentral.com/I47I-244X/7/SI/S73

(c) 2007 Hartong; licensee BioMed Central Ltd.

Dutch law provides rules for therapeutic relations. Basically therapeutic relations are agreements reached between a professional provider and a care seeker. Rules apply to treatment relations in somatic medicine as well as in psychiatry. Additional legislation (BOPZ) affects the involuntary hospitalization in psychiatric hospitals and the use of coercive treatment. Determinants for application of involuntary hospitalization are dangerous behavior in the presence of a psychiatric disorder and the lack of alternatives to avert this danger. Basic in BOPZ is the intention to rule the use of coercion on a citizen by another citizen. The states of the patient and the psychiatric professional are subordinate. Patient agreement to treatment is mandatory. Incapacity to adequate judgement of interests requires agreement to treatment by a relative. However, this does not apply to patients involuntary hospitalized in a psychiatric institution under BOPZ law. In that case patient agreement is needed for any treatment, even if the patient is incapable of adequate judgement of his interest due to the psychiatric disorder. If danger of harm is present coercive measures may be taken. The BOPZ law is consequently viewed by professionals as a hospitalization law, not as a treatment law. Jurisprudence accumulates on seclusion being judged as less intrusive than coercive medication. Although the BOPZ law has seen several adaptations, none were disorder specific. In the case of acute severe mania - a severe state that lasts for months if untreated, but responds to treatment in most cases - treatment is often refused due to lack of insight. From a psychiatric perspective BOPZ law hampers adequate psychiatric treatment of severe mania and increases patients risks both in the short and long term. High dosages of neuroleptic treatment for agitation or involuntary seclusion have to be used while adequate treatment according to guidelines is postponed. 